\title{
Incidence of Placenta Accreta and Its Complications in Cases of Previous Cesearean Sections with Placenta Praevia Anterior at El-Sayed Galal Hospital
}

\author{
Mohammed A. Mohammed, Adel A. Al-Boghdady, Islam S. Ibraheem
}

Department of Obstetrics and Gynecology, Faculty of Medicine - Al-Azhar University

Corresponding author: Islam S. Ibraheem; Mobile: 01127160615; Email: islamsaeed723@gmail.com

\begin{abstract}
Background: due to the increasing rate of cesarean delivery, there has been a 10-fold rise in the incidence of placenta accreta since the 1970. In a recent survey, placenta accreta was even found to become the leading cause of emergency peripartum hysterectomy which represented 40-60\% of cases. Aim of the Work: the purpose of this study was to determine the incidence of placenta accreta and its complications in cases of previous cesarean sections with placenta praevia anterior at El-Sayed Galal Univerity Hospital.

Patients and Methods: this prospective study was done at El-Sayed Galal Maternal Unevirsity Hospital during the period from March 2017 to March 2018 on 100 pregnant women diagnosed by ultrasound as placenta praevia or low lying placenta anterior with previous cesarean section, they were selected from Outpatient Clinic, Ultrasound Unit and women admitted in El-Sayed Galal Maternal University Hospital Departments. Results: the incidence of placenta accreta in cases of previous cesarean section with placenta praevia anterior were 63\%. Risk factors of placenta accreta were: 1) Placenta praevia with prior cesarean section. All cases had placenta praevia and had at least one previous CS, 2) Increased maternal age (the mean age 32.60 \pm 5.018 years in cases of placenta accrete ), and 29.14 \pm 4.889 years in cases with normal placenta. 3) Multiparity [the median parity was 3 (range: 1-6). The ultrasonography and Doppler was suggestive of morbid adherence in 60 cases (95.2\%) of cases approved with placenta accreta, with accuracy 96, sensiyivity 95.24, specificity $97.3,+$ ve predictive value 98.36 , and -ve predictive value 92.31 . The intraoperative data were:, Cesarean hysterectomy performed in all cases of placenta accrete (63 cases), and 2 cases $(5.4 \%)$ of normal placenta due to severe bleeding from placental ped and uterine atony. , - Bladder injury occured in 31 cases $(49.2 \%)$ all of them approved placenta accreta, all of them do C.S hystrectomy and performed bladder repair. Bowel injury in 2 cases (3.2\%) all of them have placenta accreta and C.S hysterectomy done. All cases of placenta accreta received intra operative blood transfusion. Uterine preserving procedures (Bakry balloon) done in one case after spontaneous separation of the placenta. The postoperative data were:, - ICU admission occurred in 40 cases $(63.5 \%)$ of cases with placenta accrete, and in 2 cases $(5.4 \%)$ of cases with normal placenta. 61 cases $(96.8 \%)$ of cases with placenta accreta received postoperative blood transfusion. -No cases complicated with DIC or death. Conclusion: from the above our results showed that the incidence, risk factors and Feto-maternal outcome of management of Patients with placenta accreta at El-Sayed Galal University Maternity Hospital are comparable with those in the previous literatures.

Keywords: placenta accrete, cesarean section, placenta previa anterior.
\end{abstract}

\section{INTRODUCTION}

Placenta accreta occurs when the chorionic villi invade the myometrium abnormally. It is divided into three grades based on histopathology: placenta accreta where the chorionicvilli are in contact with the myometrium, placenta increta where the chorionic villi invade the myometrium, and placenta percreta where the chorionic villi penetrate the uterine serosa ${ }^{(1)}$. The exact pathogenesis of placenta accreta is unknown. A proposed hypothesis includes a maldevelopment of decidua, excessive trophoblastic invasion, or a combination of both. Defective decidualization, abnormal maternal vascular remodeling, excessive trophoblastic invasion, or combinations are considered to be the consequences of previous instrumentation (2).The incidence of placenta accreta has been steadily increasing, mirroring increased rates of caesarean delivery over the past 50 years ${ }^{(3)}$, an incidence of 1: 533 births was reported for the period from 1982 to 2002, much greater than previous reports ranging from 1: 4027 to $1: 2510$ births in the 1970 s to 1980 s ${ }^{(4)}$, the incidence of placenta accreta is likely to continue to increase ${ }^{(5)}$. Placenta accreta is considered a severe pregnancy complication that may be associated with massive and potentially life-threatening intrapartum and postpartum hemorrhage. The severe uterine hemorrhage may lead to the need of extensive lifesaving surgical interventions such as Hysterectomy and Ligation of major pelvic vessels, placenta accreta has become the leading cause of emergency hysterectomy ( ${ }^{(\boldsymbol{)}}$. Maternal morbidity had been reported to occur in up to $60 \%$ and mortality in up to $7 \%$ of women with placenta accreta. In addition, the incidence of perinatal complications is also increased mainly due to preterm birth and small for gestational age fetuses ${ }^{(7)}$. Several risk factors for 
placenta accreta have been reported, including a previous cesarean delivery particularly when accompanied with a coexisting placenta praevia, increasing numbers of prior cesarean deliveries exponentially increase the risk of placenta accreta (4). Other predisposing factors have been identified including: scarred uterus, multiparity, previous uterine surgery, advanced maternal age, previous uterine curettage ${ }^{(8)}$. Placenta accreta is diagnosed ideally in the antenatal period by either sonographic or magnetic resonance imaging techniques. Several studies have demonstrated the usefulness of ultrasonography in making this diagnosis, particularly at $>20$ weeks' gestation. Unfortunately, some cases of placenta accreta are diagnosed at the time of delivery when the mother experiences continued vaginal bleeding, or heavy vaginal bleeding when an attempt is made to remove the placenta or only part of the placenta is able to be removed ${ }^{(9)}$.

\section{AIM OF THE WORK}

The purpose of the study was to determine the incidence of placenta accreta and its complications in cases of previous cesearean sections with placenta praevia anterior at El-Sayed Galal University hospital.

\section{PATIENTS AND METHODS}

The present study was done at El-Sayed Galal Maternal Unevirsity Hospital during the period from March 2017 to March2018. This study was a prospective study to assess the incidence of placenta accreta and its complications in cases of previous cesarean sections with placenta praevia anterior, accuracy of diagnostic test, which evaluates the accuracy of each criterion of trans abdominal color Doppler ultrasound in diagnosis of placenta previa accreta in 100 pregnant women diagnosed by ultrasound as placenta praevia or low lying placenta anterior with previous cesarean section, selected from outpatient clinic, ultrasound unit, and women admitted in El-Sayed Galal Maternal University Hospital Departments.

The study was approved by the ethics committee and after proper counseling; all women solicited for enrollment and provided written informed consent.

\section{Inclusion criteria included:}

1- Parity: patients must have placenta praevia anterior (margenalis, incomplete centralis or complete centralis) with at least one previous cesarean section.

2- Gestational age: more than 30 weeks at start of the study.

\section{3- Singleton or multiple pregnancy}

\section{Exclusion criteria:}

1. Patients with unscared uterus, or scared uterus rather than cesarean section.

2. Patients with normally situated placenta.

3. Placenta praevia posterior.

4. Coagulopathy.

\section{RESULTS}

Table 1: all parameters distribution of the studied groups

\begin{tabular}{|c|c|c|}
\hline & & Total $(\mathrm{N}=100)$ \\
\hline \multirow{3}{*}{ Accreta } & Accreta & $52(52 \%)$ \\
\hline & Increta & $37(37 \%)$ \\
\hline & Percereta & $11(11 \%)$ \\
\hline \multirow{5}{*}{ No. of P.C.S } & 1 & $21(21 \%)$ \\
\hline & 2 & $25(25 \%)$ \\
\hline & 3 & $34(34 \%)$ \\
\hline & 4 & $17(17 \%)$ \\
\hline & 5 & $3(3 \%)$ \\
\hline \multirow{2}{*}{ Bladder injury complication } & Positive & $31(31 \%)$ \\
\hline & Negative & $69(69 \%)$ \\
\hline \multirow{2}{*}{ Bowel injury complication } & Positive & $2(2 \%)$ \\
\hline & Negative & $98(98 \%)$ \\
\hline \multirow{2}{*}{ Operative blood transfusion } & Positive & $80(80 \%)$ \\
\hline & Negative & $20(20 \%)$ \\
\hline \multirow{2}{*}{$\begin{array}{c}\text { Post-Operative blood } \\
\text { transfusion }\end{array}$} & Positive & $72(72 \%)$ \\
\hline & Negative & $28(28 \%)$ \\
\hline \multirow{2}{*}{ ICU admission } & Positive & $42(42 \%)$ \\
\hline & Negative & $58(58 \%)$ \\
\hline \multirow{2}{*}{ Neonatal ICU admission } & Positive & $17(17 \%)$ \\
\hline & Negative & $83(83 \%)$ \\
\hline
\end{tabular}


This table showed that the accrete was 52 (52\%), increta was $37(37 \%)$, percereta was 11 (11\%), No. of P.C.S P.C.S1 $21(21 \%)$, P.C.S2 25 (25\%), P.C.S3 34 (34\%), P.C.S4 17 (17\%), P.C.S5 3 (3\%), bladder injury complication positive $31(31 \%)$, negative $69(69 \%)$, bowel injury complication positive was $2(2 \%)$, negative was 98 (98\%), operative blood transfusion positive was $80(80 \%)$, negative was $20(20 \%)$, post-operative blood transfusion positive was 72 (72\%), negative 28 (28\%), ICU admission positive was $42(42 \%)$, negative was $58(58 \%)$, neonatal ICU admission positive was 17 (17\%) and negative was 83 (83\%).

Table 2: relation between the number of previous cesarean section (P.C.S) and the definitive diagnosis of normal and abnormal placenta in all cases

\begin{tabular}{|c|c|c|c|c|c|}
\hline \multirow{2}{*}{\multicolumn{2}{|c|}{ No. of P.C.S }} & \multicolumn{2}{|c|}{ Definitive diagnosis } & \multicolumn{2}{|c|}{ Chi-square test } \\
\hline & & \multirow{2}{*}{$\begin{array}{c}\begin{array}{c}\text { Accreta } \\
(n=63)\end{array} \\
3\end{array}$} & \multirow{2}{*}{$\begin{array}{c}\begin{array}{c}\text { Not accreta } \\
(\mathbf{n}=\mathbf{3 7})\end{array} \\
18\end{array}$} & \multirow[t]{2}{*}{$x^{2}$} & \multirow[t]{2}{*}{$p$-value } \\
\hline \multirow{2}{*}{1} & No. & & & & \\
\hline & $\%$ & 4.76 & 48.64 & \multirow{9}{*}{31.811} & \multirow{9}{*}{$<0.001 * *$} \\
\hline \multirow{2}{*}{2} & No. & 15 & 10 & & \\
\hline & $\%$ & 23.8 & 27 & & \\
\hline \multirow{2}{*}{3} & No. & 27 & 7 & & \\
\hline & $\%$ & 42.85 & 18.91 & & \\
\hline \multirow{2}{*}{4} & No. & 15 & 2 & & \\
\hline & $\%$ & 23.8 & 5.4 & & \\
\hline \multirow{2}{*}{5} & No. & 3 & 0 & & \\
\hline & $\%$ & 4.76 & 0.00 & & \\
\hline
\end{tabular}

**p-value $<0.001 \mathrm{HS}$

This table showed that there was a high significant relation between number of previous cesarean section (P.C.S) and the definitive diagnosis of normal and abnormal placenta in all studied cases (Pvalue $<0.0001)$.

Table 3: relation between bladder injury complication and the definitive diagnosis of normal and abnormal placenta in all the studied cases

\begin{tabular}{|c|c|c|c|c|c|}
\hline \multirow{2}{*}{\multicolumn{2}{|c|}{ Bladder injury complication }} & \multicolumn{2}{|c|}{ Definitive diagnosis } & \multicolumn{2}{|c|}{ Chi-square test } \\
\hline & & \multirow{2}{*}{$\begin{array}{c}\begin{array}{c}\text { Accreta } \\
(\mathbf{n}=\mathbf{6 3})\end{array} \\
31\end{array}$} & \multirow{2}{*}{$\begin{array}{c}\begin{array}{c}\text { Not accreta } \\
(\mathbf{n}=\mathbf{3 7})\end{array} \\
0\end{array}$} & \multirow[t]{2}{*}{$x^{2}$} & $p$-value \\
\hline \multirow{2}{*}{ Positive } & $\mathrm{N}$ & & & & \multirow{4}{*}{$<0.001 * *$} \\
\hline & $\%$ & 49.2 & 0 & \multirow{3}{*}{24.136} & \\
\hline \multirow{2}{*}{ Negative } & $\mathrm{N}$ & 32 & 37 & & \\
\hline & $\%$ & 50.8 & 100 & & \\
\hline
\end{tabular}

${ }^{* *} p$-value $<0.001 \mathrm{HS}$

This table showed that there is significant relation between bladder injury complication and the definitive diagnosis of normal and abnormal placenta (P-value less than 0.0001).

Table 4: relation between bowel injury complication and the definitive diagnosis of normal and abnormal placenta in all the studied cases

\begin{tabular}{|c|c|c|c|c|c|}
\hline \multirow{2}{*}{\multicolumn{2}{|c|}{ Bowel injury complication }} & \multicolumn{2}{|c|}{ Definitive diagnosis } & \multicolumn{2}{|c|}{ Chi-square test } \\
\hline & & \multirow{2}{*}{$\begin{array}{c}\begin{array}{c}\text { Accreta } \\
(n=63)\end{array} \\
2\end{array}$} & \multirow{2}{*}{$\begin{array}{c}\begin{array}{c}\text { Not accreta } \\
(\mathbf{n}=37)\end{array} \\
0 \\
\end{array}$} & \multirow[t]{2}{*}{$x^{2}$} & \multirow{2}{*}{ p-value } \\
\hline Doritive & $\mathrm{N}$ & & & & \\
\hline I Ositive & $\%$ & 3.2 & 0 & \multirow{3}{*}{0.126} & \multirow{3}{*}{0.274} \\
\hline \multirow{2}{*}{ Negative } & $\mathrm{N}$ & 61 & 37 & & \\
\hline & $\%$ & 96.8 & 100 & & \\
\hline
\end{tabular}

p-value $>0.05 \mathrm{NS}$

This table showed that there was no significant relation between bowel injury complication and the definitive diagnosis of normal and abnormal placenta $(\mathrm{P}$-value $=0.274)$. 
Table 5: relation between operative blood transfusion and the definitive diagnosis of normal and abnormal placenta in all the studied cases

\begin{tabular}{|c|c|c|c|c|c|}
\hline \multirow{2}{*}{\multicolumn{2}{|c|}{ Operative blood transfusion }} & \multicolumn{2}{|c|}{ Definitive diagnosis } & \multicolumn{2}{|c|}{ Chi-square test } \\
\hline & & $\begin{array}{c}\text { Accreta } \\
(n=63)\end{array}$ & $\begin{array}{c}\text { Not accreta } \\
(\mathbf{n}=37)\end{array}$ & $x^{2}$ & p-value \\
\hline \multirow[b]{2}{*}{ Positive } & $\mathrm{N}$ & 63 & 17 & \multirow{4}{*}{39.256} & \multirow{4}{*}{$<0.001 * *$} \\
\hline & $\%$ & 63 & 45.9 & & \\
\hline \multirow{2}{*}{ Negative } & $\mathrm{N}$ & 0 & 20 & & \\
\hline & $\%$ & 0 & 54.1 & & \\
\hline
\end{tabular}

**p-value $<0.001 \mathrm{HS}$

This table showed that there is high significant relation between operative blood transfusion and the definitive diagnosis of normal and abnormal placenta $(\mathrm{P}-\mathrm{value}<0.0001)$.

Table 6: relation between post operative blood transfusion and the definitive diagnosis of normal and abnormal placenta in all the studied cases

\begin{tabular}{|c|c|c|c|c|c|}
\hline \multirow{2}{*}{\multicolumn{2}{|c|}{$\begin{array}{l}\text { Post Operative blood } \\
\text { transfusion }\end{array}$}} & \multicolumn{2}{|c|}{ Definitive diagnosis } & \multicolumn{2}{|c|}{ Chi-square test } \\
\hline & & $\begin{array}{c}\text { Accreta } \\
(n=63)\end{array}$ & $\begin{array}{c}\text { Not accreta } \\
(\mathbf{n}=37)\end{array}$ & $x^{2}$ & $p$-value \\
\hline \multirow{2}{*}{ Positive } & $\mathrm{N}$ & 61 & 11 & \multirow{6}{*}{48.777} & \multirow{6}{*}{$<0.001 * *$} \\
\hline & $\%$ & 96.8 & 29.7 & & \\
\hline \multirow{2}{*}{ Negative } & $\mathrm{N}$ & 2 & 26 & & \\
\hline & $\%$ & 3.2 & 70.3 & & \\
\hline \multirow{2}{*}{ Total } & $\mathrm{N}$ & 63 & 37 & & \\
\hline & $\%$ & 100.00 & 100.00 & & \\
\hline
\end{tabular}

**p-value $<0.001 \mathrm{HS}$

This table showed that there is high significant relation between post operative blood transfusion and the definitive diagnosis of normal and abnormal placenta (P-value $<0.0001$.

Table 7: relation between intensive care unit (ICU) admission and the definitive diagnosis of normal and abnormal placenta in all studied cases

\begin{tabular}{|c|c|c|c|c|c|}
\hline \multicolumn{2}{|c|}{ ICU admission } & \multicolumn{2}{c|}{ Definitive diagnosis } & \multicolumn{2}{c|}{ Chi-square test } \\
\cline { 3 - 4 } & $\begin{array}{c}\text { Accreta } \\
(\mathbf{n = 6 3})\end{array}$ & $\begin{array}{c}\text { Not accreta } \\
(\mathbf{n = 3 7 )}\end{array}$ & \multirow{2}{*}{$\boldsymbol{x}^{\mathbf{2}}$} & $\boldsymbol{p}$-value \\
\hline \multirow{2}{*}{ Positive } & $\mathrm{N}$ & 40 & 2 & \multirow{2}{*}{29.946} & $<0.001^{* *}$ \\
\cline { 2 - 4 } & $\%$ & 63.5 & 5.4 & \\
\hline \multirow{2}{*}{ Negative } & $\mathrm{N}$ & 23 & 35 & \\
\cline { 2 - 4 } & $\%$ & 36.5 & 94.6 & & \\
\hline
\end{tabular}

${ }^{* *} p$-value $<0.001 \mathrm{HS}$

This table showed that there was a high significant relation between ICU admission and the definitive diagnosis of normal and abnormal placenta (P-value $<0.0001$.

42 cases $(42 \%)$ admitted in ICU, 40 cases $(63.5 \%)$ of them were placenta accreta, and 2 cases $(5.4 \%)$ have normal placenta. While, 58 cases $(58 \%)$ not admitted in ICU, 23 cases $(36.5 \%)$ of them were placenta accreta, and 35 cases $(94.6 \%)$ have normal placenta.

Table 8: relation between the neonatal ICU admission in all the studied cases in relation to definitive diagnosis of normal and abnormal placenta

\begin{tabular}{|c|c|c|c|c|c|c|}
\hline \multirow{3}{*}{$\begin{array}{l}\text { Neonatal ICU } \\
\text { admission }\end{array}$} & \multicolumn{4}{|c|}{ Definitive diagnosis } & \multirow{2}{*}{\multicolumn{2}{|c|}{ Chi-square test }} \\
\hline & \multicolumn{2}{|c|}{$\begin{array}{c}\text { Accreta } \\
(n=63)\end{array}$} & \multicolumn{2}{|c|}{$\begin{array}{c}\text { Not accreta } \\
(\mathbf{n}=\mathbf{3 7})\end{array}$} & & \\
\hline & No. & $\%$ & $\mathbf{N}$ & $\%$ & $x^{2}$ & p-value \\
\hline Positive & 9 & 14.3 & 8 & 21.6 & \multirow{2}{*}{0.445} & \multirow{2}{*}{0.505} \\
\hline Negative & 54 & 85.7 & 29 & 78.4 & & \\
\hline
\end{tabular}

p-value $>0.05 \mathrm{NS}$

This table showed that there is no significant relation between the neonatal ICU admission and pathological definitive diagnosis of normal and abnormal placenta in all studied cases ( $\mathrm{P}$-value $=0.346$ ). 
Table 9: description of neonatal APGER score in all the studied cases

\begin{tabular}{|c|c|c|c|c|}
\hline \multirow{2}{*}{$\begin{array}{c}\text { Neonatal APGER } \\
\text { score }\end{array}$} & \multicolumn{2}{|c|}{ MEAN \pm SD } & \multicolumn{2}{|c|}{ t-test } \\
\cline { 2 - 5 } & $\begin{array}{c}\text { Accreta } \\
(\mathbf{n}=\mathbf{6 3})\end{array}$ & $\begin{array}{c}\text { Not accreta } \\
(\mathbf{n}=\mathbf{3 7})\end{array}$ & $\boldsymbol{t}$ & $\mathbf{p}$-value \\
\hline Mean \pm SD & $7.05 \pm 0.974$ & $6.65 \pm 1.274$ & 0.942 & 0.105 \\
\hline
\end{tabular}

This table showed that there were no significant relation between neonatal APGER score and definitive diagnosis of normal and abnormal placenta in all cases, as $\mathrm{p}$ value 0.105 .

Examples of microscopic picture of abnormal placenta from Pathological Department in El-Sayed Galal University Hospital.

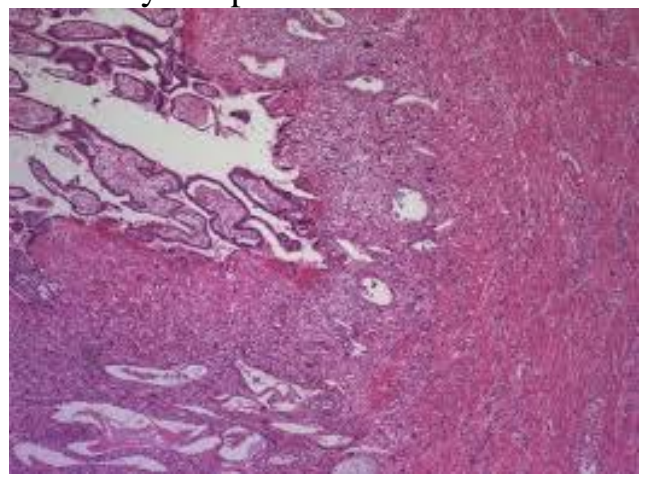

Figure 1: placental tissue adherent to myometrium\&partially invading it, (picture of placenta accreta).

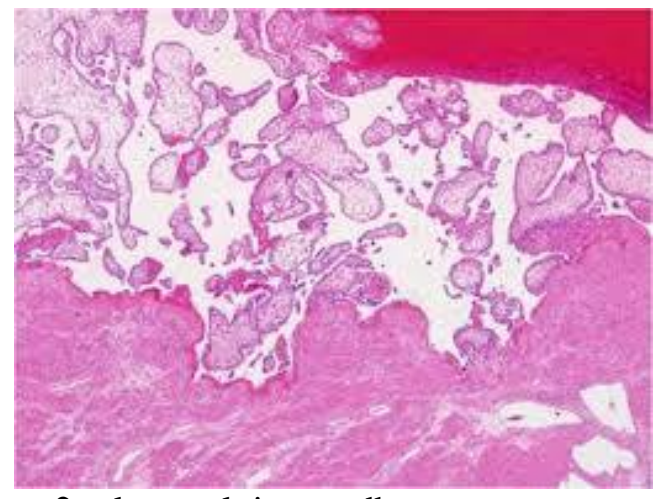

Figure 2: placental tissue adherent to myometrium\& invading more than half of myometrium \&not reaching the serosa, (picture of placenta increta).

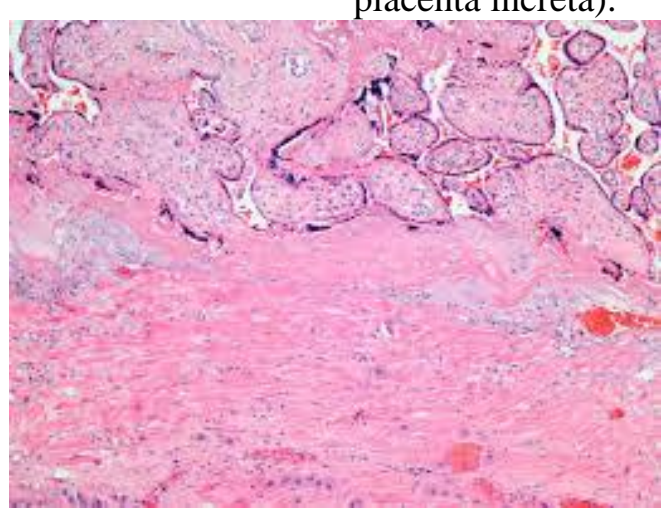

Figure 3: placental tissue adherent to myometrium and invading more than half of myometrium \&reaching the serosa, (picture of placenta percreta).

\section{DISCUSSION}

Placenta accreta is considered as severe pregnancy complication that may be associated with massive and potentially life-threatening intrapartum and postpartum hemorrhage, and so it has become the leading cause of emergency hysterectomy which represents $40-60 \%$ of cases ${ }^{(6)}$.Maternal morbidity had been reported to occur in up to $60 \%$ and mortality in up to $7 \%$ of women with placenta accrete ${ }^{(7)}$.

The present study was observational prospective study of the incidence of placenta accreta and its complications in cases of previous cesarean section with placenta praevia anterior and the accuracy of color Doppler ultrasound in diagnosis of placenta accreta, conducted at ElSayed Galal University Maternal Hospital in which one hundred pregnant women diagnosed by ultrasound as placenta praevia anterior with previous cesarean section were examined by color Doppler ultrasound to evaluate the accuracy of each criterion of color Doppler ultrasound in diagnosis of placenta praevia accreta. The incidence of placenta accreta was likely to continue to increase ${ }^{(5)}$.

Until2002the incidence was 1 in 533 deliveries, but in 2006, the incidence increased up to 1 in 210 deliveries ${ }^{(\mathbf{1 0})}$.In our study, the incidence of placenta accreta in cases of previous cesarean section with placenta praevia anterior was $63 \%$ The marked increase in the incidence has been attributed to the increasing prevalence of cesarean delivery in recent years and we select more than risk factors in the inclusion criteria of patients included in the study (previous cesarean, placenta praevia anterior reaching the scar, and the cases collected from El-Sayed Galal University Maternity Hospital). Wu et al. ${ }^{(4)}$ reported that 
placenta accreta was much more common than placenta increta and percreta with the following incidences: placenta accreta $-79 \%$; placenta increta - 14\%; and placenta percreta $7 \%$. Results of our study agree with those of $\mathbf{W u}$ et $\boldsymbol{a l} .{ }^{(4)}$ as placenta accreta was more common than increta and percreta. In our study the incidences of abnormal placentation: $50.8 \%$ (32 cases) placenta accreta; $34.9 \%$ (22 cases) placenta increta and $14.3 \%$ (9 cases) placenta percreta. Silver et al. (11) demonstrated the relation between the placenta accreta and the number of cesarean deliveries in women with placenta praevia, Silver et al. ${ }^{(11)}$ reported that in women with placenta praevia, the frequency of placenta accreta increases with an increasing number of cesarean deliveries as follows: in women with placenta praevia and no previous cesarean birth 1 to $5 \%$, with one previous cesarean birth 11 to $25 \%$, with two previous cesarean birth 35 to $47 \%$, with three previous cesarean births $40 \%$, and with four or more previous cesarean births 50 to $67 \%$. Results of this study agree with those of Silver $\boldsymbol{e t}$ al. ${ }^{(\mathbf{1 1 )})}$ as in our series 100 pregnant women, diagnosed by Gray scale ultrasound as placenta praevia anterior margenalis, incomplete centralis or centralis, all of them were with past history of previous cesarean section, at a mean age 29 years, mean gestational age of 35 weeks. Our study showed significant relation between abnormal placenta (accreta, increta, or percreta) and number of previous cesarean sections, as whenever the number of previous cesarean section (P.C.S) increased the frequency of abnormal placenta also increased, $14.2 \%$ with one previous cesarean section, $60 \%$ with two previous cesarean section, $79.4 \%$ with three previous cesarean section, $88.23 \%$ with four previous cesarean section, and 3 cases with five previous cesarean section all of them were accreta.

According to this study the 100 studied cases were divided according to the color Doppler finding (CDF) into two groups; the first was39 cases with normal $\mathrm{CDF}$, while the second group was 61 cases with abnormal CDF. We found that, 35 women in the first group of 39 cases with normal CDF, performed C.S only without hysterectomy, and 2 women in the first group of 39 cases with normal CDF, performed cesarean hysterectomy in spite of placental separation due to uterine atony and uncontrolled bleeding from placental bed, and 2 women performed cesarean hysterectomy due to placental invasion to the myometrium and failure of placental separation and pathological examination prove placenta accreta diagnosis, the $2^{\text {nd }}$ group 61 cases $(61 \%)$ of abnormal CDF during the operation 60 cases $(95.2 \%)$ were in need for cesarean hysterectomy to achieve complete homeostasis due to severe intrapartum hemorrhage resulted from failure of placental separation in all patients, while one case (2.7\%) sever uncontrolled atonic uterine bleeding after placental separation and uncontrolled bleeding from placental ped. All patients who performed C.H, underwent histopathological examination.According to the presence or absence of myometrial invasion, the results of histopathology confirmed the diagnosis of abnormal placenta (accreta, increta, orpercreta) in 60/61 cases with abnormal CDF, so the 60 cases were true positive cases, while the remaining case were confirmed to have no pathology, so the 1 case was false positive case and she need C.S but exaggerated bleeding from placental bed controlled by ecbolics and Bakry ballon. The second group with normal CDF suggesting normal placenta were 39, According to the end results of operative management and histopathological examination, the definitive diagnosis of normal placenta was confirmed in 37/100 cases, [the greater proportion of them (36/39) were with -ve CDF (true -ve cases), and the remaining (3/39) were with - veCDF (false negative cases)]. While, the definitive diagnosis of abnormal placenta was confirmed in $63 / 100$ cases all of them managed by cesarean hysterectomy.

So this study demonstrated that there was a high significant relation between the definitive diagnosis of placenta accreta and the antenatal color Doppler diagnosis of placenta accreta, and so we agree with Glaze $\boldsymbol{e t}$ al. ${ }^{(12)}$ as we all demonstrated that antenatal diagnosis of placenta praevia accreta will allow planned cesarean hysterectomy in suspected cases, which significantly help in decreasing the rate of morbidity and mortality due to massive bleeding.

ACOG ${ }^{(13)}$ demonstrated that if the color Doppler finding revealed placenta accreta, the patient has an $80 \%$ likely hood of undergoing hysterectomy. Results of this study agree with those of ACOG ${ }^{(\mathbf{1 3})}$ as in our study, color Doppler finding revealed placenta accreta in 61 patients, $98.3 \%$ of these patients underwent hysterectomy.Another study showed that use of color Doppler imaging can improve the accuracy of the diagnosis of placenta accreta since the depth of invasion of the placenta into the uterine myometrium or serosa can be more accurately determined, especially in cases where the placenta is located anteriorly ${ }^{\left({ }^{(9)}\right.}$.ACOG ${ }^{(\mathbf{1 3})}$ demonstrated that color Doppler ultrasound in diagnosis of placenta accreta had sensitivity $82.4 \%$, specificity 96.8\%, PPV and NPV were $87.5 \%$ and $95.3 \%$ respectively. This study demonstrated that color Doppler ultrasound in diagnosis of placenta accreta 


\section{Mohammed Mohammed et al.}

had very high sensitivity $95.24 \%$, NPV $92.32 \%$, accuracy 96\%, specificity $97.30 \%$, and PPV $98.36 \%$.Chou et al. calculated the sensitivity, specificity, PPV and NPV by a combined assessment of all criteria using gray-scale ultrasound or color Doppler ${ }^{(14)}$.

The risk of performing an unnecessary hysterectomy (false positive), or the risk of secondary bleeding following attempted placental removal (false negative) should always be considered. An evaluation based only on sensitivity and specificity is not sufficient to legitimize the use of diagnostic criteria; assessment of PPV and NPV is mandatory in planning appropriate management of the patients, the high PPV justifies more aggressive management, while a high NPV justifies an attempt to remove the placenta without risk of major bleeding complications ${ }^{(15)}$.Practically, PPV reported for each criterion indicated its reliability to correctly diagnose placenta accreta; in other words, the confidence with which the clinicians can proceed straight to hysterectomy without removing the placenta. In contrast, the NPV represents the precision of diagnosis of placenta praevia ${ }^{(15)}$.Despite the modern advances in imaging techniques, no single diagnostic criterion affords complete assurance for the presence or absence of placenta accrete ${ }^{(16)}$.

In the current study, each criterion of the color Doppler ultrasound in all studied cases was described. PPV, NPV, sensitivity, specificity and accuracy of each criterion were calculated separately as follow:

Sonolucent area (A) criteri, it was preserved in 41/100 cases, and absent in the remaining 59/100 cases, according to the definitive diagnosis of normal and abnormal placenta by pathological examination, it was found that $\mathrm{A}$ criterion had 55 true +ve cases, 4 false +ve cases, 33 true -ve cases, and 8 false -ve cases. So this criterion had high specificity $89.19 \%$, NPV $93.22 \%$, accuracy $88 \%$, PPV $84 \%$, and sensitivity $87.30 \%$.Lacunae (D) criteria, was detected in $73 / 100$ cases and not detected in 27/100 cases, 59 cases with were true +ve cases, also had 23 true ve cases, and 4 false -ve cases, and 14 false +ve cases, So lacunae had the highest sensitivity value 93.65\% and the highest NPP 85.19\%, 62.16\% specifecity, $80.82 \%$ PPV, and $82 \%$ accuracy.

Hypervascularity in uterine bladder interface $(\mathrm{H})$ criteria, it was detected in $32 / 100$ cases, and not detected in 68/100 cases, (30 true +ve cases, 2 false +ve cases, 35 true -ve cases, and 33 false -ve cases. So (H) criterion had high specificity $94.59 \%$, NPV $51.47 \%$, accuracy $65 \%$, PPV $93.75 \%$ and sensitivity $47.62 \%$.
This study confirmed that lacunae (D) criterion was the most sensitive, with the highest NPV, than all other criteria of color Doppler ultrasound, and loss of plane of cleavage (A) criterion had the highest specificity and highest PPV, than all other criteria of color Doppler ultrasound, We also noted that hypervascularity in uterine bladder interface (H) criterion had the lowest NPV of $51.47 \%$ than other criteria. Similarly in Cali et al. ${ }^{\left({ }^{(17)}\right.}$ study, 187 patients with placenta praevia and history of uterine surgery performed transabdominal 2D gray scale, color Doppler, and 3D power Doppler ultrasound for early detection of morbidity adherent placenta, and to evaluate the diagnostic accuracy of their criteria. Morbidity adherent placenta was detected on C.S in 41 patients, hysterectomy was performed, and pathological examination confirmed the diagnosis of morbidity adherent placenta in all 41 cases.

Results of our study agree with the study of Cali et al. ${ }^{(17)}$ which was done on 134 pregnant with placenta praevia demonstrated that $(\mathrm{H})$ criterion by color Doppler ultrasound had the best diagnostic performance, as it was illustrated in the results tables with the highest PPV 96\%, and highest specificity $99 \%$, And we demonstrated that (H) criterion had $93.75 \%$ PPV and $94.59 \%$ specificity.In contrast with this study Cali et al. ${ }^{(17)}$ found that (A) criterion of color Doppler ultrasound had high NPV 97\%, but also was responsible for the most false positive cases, had the lowest PPV of $57 \%$ than other criteria, and this low PPV suggested that (A) criterion should not be used alone in diagnosis of morbidity adherent placenta, while in our study (A) criterion had high PPV 93.22\%.In another study of Shih et al. ${ }^{(15)}, 170$ pregnant women with persistent placenta praevia were prospectively enrolled, 3D power Doppler was used to compare its diagnostic performance with color Doppler ultrasound.

The diagnosis of placenta accreta was regarded as positive when any one of the color Doppler criteria was present. Placenta accreta was diagnosed in 39 patients; all had a past history of prior cesarean delivery except one case.

The mean gestational age at sonographic diagnosis of placenta accreta was $30.7 \pm 2.2$. Among these patients 37 patients underwent C.H in order to prevent massive postpartum hemorrhage. The remaining 2 patients underwent focal resection of myometrium invaded by placenta. The final pathological analysis revealed 6 cases of placenta accreta, 24 cases of placenta increta and 9 cases of placenta percreta. According to the group who had past history of C.S in this study, Shih et al. (15) found that (D) and (H) criteria led to the most false positive diagnosis by color Doppler ultrasound. 
According to $(\mathrm{H})$ criterion, this study agrees with Shih et al. ${ }^{(15)}$ study, as in this study (H) and (A)criteria led to most false positive diagnosis, but (A) criterion of color Doppler ultrasound was not discussed in Shih et al. ${ }^{(15)}$ study. But according to (D) criterion, this study doesn't agree with Shih et al. ${ }^{(15)}$ study, as on contrast we confirmed that 59 cases $(93.7 \%$ ) with (D) criterion were true positive, and 14 cases $(37.8 \%)$ false +ve.Shih et al. ${ }^{(15)}$ surprisingly found that, the PPVs of most criteria for diagnosing accreta were high. Also vascular lacks with turbulent lacunar blood flow (F) criterion was illustrated in the results tables with the highest specificity 94\%, and the highest PPV $91 \%$, than other criteria of color Doppler ultrasound. Results of our study agrees with results of Shih $\boldsymbol{e t}$ al. ${ }^{(15)}$ as the PPVs of most criteria for diagnosing accreta in our study were high.

In Japaraj et al. ${ }^{(18)}$ study, 21 patients who had undergone previous cesarean sections and were confirmed to have partial or total placenta praevia in the current pregnancy, they were subjected to ultrasound examinations after the 28th week of gestation.

Specific ultrasound features were looked for on gray-scale ultrasound and color Doppler examination. 7 of the 21 patients had color Doppler ultrasound evidence of placenta accreta. The most prominent color Doppler feature present in all seven patients, was the presence of $(\mathrm{H})$ criterion. The next most common feature of placenta accreta was the presence of (D) criterion. During the operative management of the patients, five out of the seven patients underwent peripartum hysterectomy to control massive intraoperative bleeding. The five patients who underwent hysterectomy had a histopathological confirmation of placenta accreta. The 2 patients who did not have a hysterectomy were noted to have adherent pieces of placenta but not bleed profusely. According to the results of histopathology $(\mathrm{H})$ criterion confirmed the diagnosis of placenta accreta in 5/5 cases, while (D) criterion confirmed the diagnosis of placenta accreta in $4 / 5$ cases. Japaraj $\boldsymbol{e t}$ al. ${ }^{(\mathbf{1 8})}$ study, also showed that sometimes $(\mathrm{H})$ criterion could be mistaken for bladder varices arising from neovascularized vessels from previous cesarean deliveries, in our study one case have +ve H criteria and during the surgery it was just a bladder varices and C.S only without hysterectomy done and bleeding from placental bed controlled by Bakry bollon, these one of false $+v e$ cases of $\mathrm{H}$ criteria. Results of our study agree with results of Japaraj et al. ${ }^{(18)}$ who confirmed that $(\mathrm{H})$ criterion was the most specific and the best diagnostic one, then (A) criterion had the second best diagnostic value of color Doppler ultrasound. Also (A) and (F) criteria of color Doppler were not discussed in Japaraj $\boldsymbol{e t}$ $\boldsymbol{a l}$. study, while in our study they were discussed in details.

Japaraj et al. ${ }^{(18)}$ didn't calculate the sensitivity, specificity, PPV and NPV of each color Doppler criterion separately, but our study calculated them. Of the included 63 women with morbidly-adherent placenta praevia, $42(66.7 \%)$ presented with antepartum hemorrhage (APH).Morbidity from placenta accreta is caused by problems associated with massive bleeding. In the present study, 100 cases 63 of them definitive diagnosis of abnormal placenta all need intra operative blood transfusion, while the 37 cases with normal placenta 17 cases (45.9\%) need intra operative blood transfusion and 26 cases $(70.3 \%)$ need not blood transfusion.Post operative blood transfusion needed in 61 cases (96.8\%) of accreta cases, and 2 cases don't need post operative blood transfusion, while 11 case (29.7\%) of normal placenta need blood transfusion, and 26 cases $(70 \%)$ need not postoperative blood transfusion. The present findings agree with those of Warshak $\boldsymbol{e t}$ al. ${ }^{(5)}$, which analyzed 99 placenta accreta cases, found that approximately $75 \%$ required blood transfusion with a mean of $5.4 \pm 2.1$ units of RBCs.

Thus, blood transfusion should be anticipated, and massive transfusion is not rare in these obstetric patients. In the current study 63cases of accreta 40 of them $(63.5 \%)$ admitted in ICU and 23 cases $(36 \%)$ not admitted in ICU, while 37 cases of normal placenta 2 cases $(5.4 \%)$ admitted in ICU and 35 cases $(94.6 \%)$ not admitted in ICU. No cases in our study complicated with DIC (disseminated intravascular coagulopathy) may be due to the sample size.Other causes of early morbidity (coagulopathy, admission to the intensive care units, bladder injury and bowel injury ) are also high in patients with placenta accreta, as reported in previous study ${ }^{(7)}$.

A retrospective study of 76 women with placenta accrete, bladder injury was observed in 22 cases (49\%) \& ICU admission in 21 cases (54\%).In our study the bladder was injured and repaired in 31 of 63 cases $(49.2 \%)$ all of them with abnormal placenta, while no bladder injury in cases of normal placenta. Bowel injury happen in 2 cases only (3.2\%) all have abnormal placenta, while no bowel injury in cases of normal placenta.In cases of placenta accreta the incidence of perinatal complications is also increased mainly due to preterm birth and small for gestational age fetuses (7). In the present study, the mean gestational age at delivery was $35 \pm 2.819$ weeks' gestation, the mean APGER score in cases of abnormal placenta 
Mohammed Mohammed et al.

$7.05 \pm 0.974$ with no significant relation (p-value0. 105).

Admission in neonatal ICU 9 cases (14.3\%) of abnormal placenta admitted in NICU, while54 cases (85.7\%) not admitted in NICU with no significant relation ( $\mathrm{p}$-value0.346). Maternal mortality has been reported in up to $7 \%$ of cases ACOG ${ }^{(\mathbf{1 9})} .109$ cases of placenta accreta maternal death in 8 cases $(7 \%)$. In the current study, there were no maternal deaths. This may be due to the sample size that was insufficient to detect the actual maternal mortality in these obstetric patients, diagnosed preoperatively, adequate blood, very experience surgical team and availability of resources improve maternal and fetal outcome and decrease maternal and fetal mortality.

\section{CONCLUSION}

Our results showed that the incidence, risk factors and feto-maternal outcome of management of Patients with placenta accreta at El-Sayed Galal University Maternity Hospital are comparable with those in the previous literatures.

\section{REFERENCES}

1. Tan CH, Tay KH, Sheah K, Kwek K, Wong K and Tan HK (2007): Perioperative endovascular internal iliac artery occlusion balloon placement in management of placenta accreta. Am .J. Roentgenol., 189:1158-63.

2. Tantbirojn P, Crum CP and Parast MM (2008): Pathophysiology of placenta creta: the role of decidua and extravillous trophoblast. Placenta, 29(7):639-645.

3. Hamilton BE, J. Martin A, Ventura SJ, Sutton PD and F Menacker (2005): Births. Preliminary Data for National Vital Statistics Reports, 54(8): 1-17.

4. Wu S, Kocherginsky M and Hibbard JU (2005): Abnormal placentation: twenty-year analysis. Am. J. Obstet. Gynecol., 192(5): 1458-1461.

5. Warshak CR, Ramos GA, Eskander R, Benirschke K, Saenz CC, Kelly TF, Moore TR and Resnik R (2010): Effect of predelivery diagnosis in 99 consecutive cases of placenta accreta. Obstet. Gynecol., 115(1):65-69.

6. Daskalakis G, Anastasakis E, Papantoniou N, Mesogitis S and Theodora M (2007): Emergency obstetric hysterectomy. Acta Obstetricia et Gynecologica Scandinavica, 86(2):223-227.

7. Eller G, Porter TT, Soisson P, and Silver RM (2009): Optimal management strategies for placenta. International Journal of Obstetrics and Gynaecology, 116(5): 648-654.

8. Turgut A, Ozler A, Evsen MS, Soydinc HE, Goruk NY, Karacor T and Gul T (2013): Uterine rupture revisited: Predisposing factors, clinical features, management and outcomes from a tertiary care center in Turkey. Pakistan Journal of Medical Sciences, 29(3):753-762.

9. Comstock CH (2005): Antenatal diagnosis of placenta accreta: a review. Ultrasound Obstet .Gynecol., 26:8996.

10. Stafford I and Belfort $M$ (2008). Placenta accreta, increta, and percreta: a team-based approach starts with prevention. Contemp. Ob. Gyn., 53 (4): 76-82.

11. Silver RM, Landon MB, Rouse DJ, Leveno KJ, Spong CY and Thom EA (2006): Maternal morbidity associated with multiple repeat cesarean deliveries. Obstetrics and Gynecology, 107 (6): 1226-1232.

12. Glaze S, Ekwalanga P, Roberts G, Lange I, Birch C, Rosengarten A, Jarrell J and Ross S (2008): Peripartum hysterectomy: 1999 to 2006. Obstet .Gynecol., 111(3):732-738.

13. ACOG (2002): Placenta accreta. Obste.t Gynecol., 99: 169-170.

14. Chou M, Ho E and Lee Y (2000): Prenatal diagnosis of placenta previa by transabdominal color Doppler ultrasound. Ultrasound Obstet. Gynecol., 15 (1): 28-35.

15. Shih JC, Palacios Jaraquemada JM, Su YN, Shyu MK, Lin CH, Lin SY and Lee CN (2009): Role of three-dimensional power Doppler in the antenatal diagnosis of placenta accreta: comparison with grayscale and color Doppler techniques. Ultrasound Obstet. Gynecol., 33: 193-203.

16. ACOG (2006): Postpartum hemorrhage. Obstet. Gynecol, 108:1039-1047.

17. Calì G, Giambanco L, Puccio $G$ and Forlani $K$ (2013): Morbidly adherent placenta: evaluation of ultrasound diagnostic criteria and differentiation of placenta accrete from percreta. Ultrasound Obstet .Gyneco., 41: 406-412.

18. Japaraj RP, Mimin TS and Mukudan K (2007): Antenatal diagnosis of placenta previa accreta in patients with previous cesarean scar. J. Obstet .Gynaecol. Res., 33(4):431-437.

19. ACOG (2010): Placenta accreta. Obstet.Gynecol., 203:430-439. 